\title{
Preliminary characterization of the dominant baroclinic modes of a tropical Andean reservoir during a dry period
}

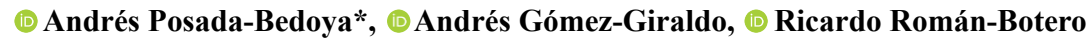 \\ Departamento de Geociencias y Medio Ambiente, Universidad Nacional de Colombia, Medellín, Colombia
}

\begin{abstract}
Field data and a simplified numerical model were used to investigate the dominant basin-scale internal waves in a tropical Andean reservoir during a dry period. The structure and period of the observed baroclinic oscillations were inferred from spectral analysis of the measured temperature records and the associated isotherm displacements. The dominant oscillation identified from the field data had a vertical structure made of two layers with vertical velocities oscillating out of phase (V2 mode) with a period of $24 \mathrm{~h}$. The theoretical baroclinic vertical modes of the reservoir were estimated by using a simplified eigenfunction model that reproduced the period and vertical structure of the observed dominant mode, indicating also that the horizontal velocity oscillations in every layer were in phase (V2H1 mode) with a period close to $24 \mathrm{~h}$. The wind forcing exhibited a periodic behavior dominated by the 24-h period component and, thus, we concluded that a V2H1 mode was dominant during the survey analyzed and it was excited by resonance with the diurnal wind-forcing. We modeled the reservoir as a linear damped forced mass-spring system to estimate the damping ratio of the baroclinic oscillations and we found that the motions were underdamped with a damping rate similar to the reported in other lakes around the globe. In addition, we estimated the gradient Richardson number due to the dominant V2H1 baroclinic mode and we found that the potential diapycnal mixing by shear was low. Finally, we discuss the vertical structure of the phase of the internal wave oscillations and the potential implications of the identified internal wave field for the ecology of the reservoir. (C) 2019. Acad. Colomb. Cienc. Ex. Fis. Nat.
\end{abstract}

Key words: Baroclinic modes; Internal waves; Eigenmodes; Tropical Andean reservoir.

Caracterización preliminar de los modos baroclínicos dominantes de un embalse tropical andino durante un período seco

\section{Resumen}

A partir de datos de campo y un modelo numérico simple, se investigaron las ondas internas a escala de cuenco en un embalse tropical andino durante un período seco. La estructura y el período de las oscilaciones baroclínicas observadas, se infirieron a partir del análisis espectral de las series de temperatura medidas y de los desplazamientos verticales de las isotermas asociadas. El modo de oscilación dominante identificado a partir de los datos de campo constaba de dos capas que oscilaban con velocidades verticales y fases contrarias (modo V2), y con un período de $24 \mathrm{~h}$. Los modos baroclínicos verticales teóricos del embalse se estimaron a partir de un eigenmodelo simple, el cual predijo el período y la estructura vertical del modo dominante identificado a partir de las observaciones, indicando también que las oscilaciones de la velocidad horizontal en cada capa estaban en fase (modo V2H1) y con un período natural cercano a $24 \mathrm{~h}$. El forzamiento del viento mostró una variabilidad periódica con un período dominante cercano a las $24 \mathrm{~h}$, por lo que concluimos que el modo V2H1 fue el dominante durante el período analizado y sometido a excitación por resonancia con el forzamiento diurno del viento. Se modeló el embalse como un sistema lineal masa-resorte, amortiguado y forzado, con el fin de estimar la relación de amortiguamiento de las oscilaciones baroclínicas, y se obtuvieron oscilaciones subamortiguadas con una tasa de amortiguamiento similar a la reportada en otros lagos alrededor del mundo. También se investigó el potencial del modo V2H1 en la generación vertical de turbulencia debido a inestabilidades cortantes usando el número de Richardson del gradiente, y encontramos que la producción de turbulencia era baja. Por último, se discuten aquí la estructura vertical de la fase en las oscilaciones de las ondas internas y las potenciales implicaciones del campo de ondas internas en la ecología del embalse. (C) 2019. Acad. Colomb. Cienc. Ex. Fis. Nat.

Palabras clave: Modos baroclínicos; Ondas internas; Eigenmodos; Embalse tropical Andino. 


\section{Introduction}

The existing literature on physical limnology and its linkage with the water quality of temperate inland waters is prolific. However, the investigations in the tropics, and particularly in the tropical Andes, are scarce in spite of the fast growing of human populations in tropical regions, which has created serious environmental problems during the last decades for tropical lakes and reservoirs (Nilssen, 1984; Parinet, et al., 2004). Tropical lakes differ from temperate lakes in a variety of aspects (Lewis Jr., 1987; Lewis Jr., 1996) and are likely more sensitive to environmental changes (climate, land use, population, invasive species, pollution) than temperate lakes (Lewis Jr., 2000). However, historical emphasis on the study of temperate lakes has biased our understanding of tropical lakes functioning in the context of physical and biogeochemical responses.

In the particular case of Colombia, numerous reservoirs for hydropower generation and water supply have been constructed during the last few decades to satisfy the growing energy and water demands of the country. Management of these reservoirs requires extensive knowledge and understanding of the physical processes responsible for water circulation, which influence directly water quality, demanding clarification of the predominant processes and time scales over which they evolve (Mortimer, 1974; Mortimer, 2004). Under this context, this paper focuses on the description of basin-scale internal waves, a predominant physical process, in a tropical Andean reservoir and discusses possible consequences on the water quality.

Stratified lakes and reservoirs can be regarded as threedimensional, mechanical, viscously damped oscillators characterized by an infinite spectrum of baroclinic (i.e., internal motions in which isopycnal surfaces oscillate) oscillatory natural modes with characteristic periods and spatial structures (Monismith, 1985; Lemmin, et al., 2005; Shimizu, et al., 2008; Valerio, et al., 2012). The characteristics of these natural modes depend on the shape of the basin and the vertical structure of the density field (Münnich, et al., 1996; Fricker \& Nepf, 2000) and are fundamental to the ecological functioning of lakes and reservoirs as they drive a variety of physical, chemical and biological processes (MacIntyre, et al., 1999; Eckert, et al., 2002; Serra, et al., 2007; Evans, et al., 2008; Hingsamer, et al., 2014). These internal waves can produce turbulence and mixing through different mechanisms, such as the increased shear at the lake interior (Horn, et al., 2001; Preusse, et al. 2010; Bouffard, et al., 2012, Ulloa, et al., 2015), interaction with the bathymetry, and a cascade of energy from basin-scale to high-frequency internal waves (Imberger, 1998; Boegman, et al., 2003; Wüest \& Lorke, 2003; Gómez-Giraldo, et al., 2008). The basin-scale internal waves play an important role in the development of the turbulent boundary layer (Lemckert, et al., 2004; Lorke, et al., 2005; Simpson, et al., 2011) and can resuspend sediments and nutrients from the bottom and reincorporate them into the water column (Gloor, et al., 1994; Pierson \& Weyhenmeyer, 1994).

The natural modes are classified depending on the number of nodal points they have in the horizontal $(j)$ and vertical (i) directions as $\mathrm{ViH} j$ (Figure 1S, https://www.raccefyn.co/ index.php/raccefyn/article/downloadSuppFile/799/3895). The most commonly observed vertical baroclinic response is the V1 (Mortimer, 1953); however, higher vertical modes are not unusual (e.g., Wiegand \& Chamberlain, 1987; Vidal, et al., 2005; Vidal \& Casamitjana, 2007; Pannard, et al., 2011; Lorrai, et al., 2011; Ulloa, et al., 2018). The difference in the spatial structure of the modes leads to advection and mixing in different locations and, thus, it can drive mixing and turbulence at specific zones of the water column where high shear occurs (Wiegand \& Chamberlain, 1987; MacIntyre, et al., 1999; Hondzo \& Haider, 2005; Henderson, 2016). The vertical structure of the oscillations can influence the circulation patterns in the lake (Vidal, et al., 2005; Vidal, et al., 2007; Ulloa, et al., 2018) and affect the properties of the water withdrawn for the reservoir operation (Anohin, et al., 2006), as well as the routes followed by substances and species entering to the reservoir from the inflow discharges (Cortés, et al., 2014; Hogg, et al., 2018). Vertical one modes typically lead to stronger dissipation around the basin perimeter through the turbulent boundary layer, while higher order vertical modes tend to dissipate more of its energy through increased shear at the interior of the lake (Simpson, et al., 2011).

The description of the natural modes has been accomplished in the literature by the implementation of models with simple horizontal geometries (e.g., rectangular, circular, elliptical) and flat bottoms for layered (Heaps \& Ramsbottom, 1966; Csanady, 1967; Antenucci \& Imberger, 2001) and continuous stratification (Csanady, 1972; Monismith, 1987). However, they reveal little about real sloping bottoms. Münnich (1996) and Fricker \& Nepf (2000) proposed two-dimensional eigenvalue numerical models taking account for a 2D arbitrary morphometry and continuous stratification. On the other hand, there is a family of eigenvalue layer-stratified models with irregular bathymetry that can incorporate better the two-dimensional (horizontal) features of the morphometry and have shown to accurately predict the natural modes of oscillation (Schwab, 1977; Bäuerle, 1998; Shimizu, et al., 2007). In this work, we used a simple eigenmodel of the family of the rectangular flat bottom (Gill, 1982) to support our observations, even though we recognize the existence of more advanced models.

Previous studies have dealt with internal waves in Colombian inland waters (Vélez-Castaño \& Gómez-Giraldo, 2011; Posada-Bedoya, et al., 2017). However, none of them have been focused on the characterization of the internal waves during dry seasons. The dry season stratification particularly imposes a major restriction for the vertical mixing of the water column compared to other hydrological seasons of the tropical Andes hydrology and, thus, it is of critical interest 
for the water quality of the reservoir. Our objective was to make a first approach to the characterization of the dominant basin-scale baroclinic response of a tropical Andean reservoir during a dry hydrological period from the analysis of field measurements complemented with a numerical eigenmodel. We also investigated the nature of the damping of the oscillations and the diapycnal mixing associated with the baroclinic modes. With this work, we expect to motivate future research on tropical Andean inland waters of Colombia and highlight the relevance of the physical processes for the water quality of these water bodies.

In this paper, we describe the study site, measurements, data analysis procedure, and the natural eigenfunction model. We describe the evolution of the external forcing and the thermal structure during the survey. Then, we depict the measured internal wave field from spectral analysis of the field data and present the theoretical natural modes by using the eigenmodel. With the aim to show the role of the wind forcing in the excitation of the internal waves, we assimilated the reservoir as a linear damped forced mass-spring system and estimated the damping ratio of the dominant baroclinic mode. Finally, we estimated the potential diapycnal mixing by shear due to the baroclinic modes and summarized the scopes of the numerical model and the relevance of the results for the reservoir ecology.

\section{Materials and methods}

Study site. Porce II is a reservoir for hydroelectric power generation located in Antioquia, Colombia. It is a $10-\mathrm{km}$ long, 1-km wide canyon reservoir with a maximum depth of $\sim 94 \mathrm{~m}$ (Figure 1). The reservoir is situated in a valley sheltered by mountains running parallel to its main axis. The surrounding topography influences the wind pattern over the reservoir (see wind roses in Figure 1) inducing a dominant component following the canyon axis that blows every afternoon (Largo-Gaviria, 2011). The reservoir receives the waters of the Porce River, which is its main tributary. Temperature is the dominant parameter in the density stratification of the dry season, with no practical effect of salinity or suspended solids (Largo-Gaviria, 2011).

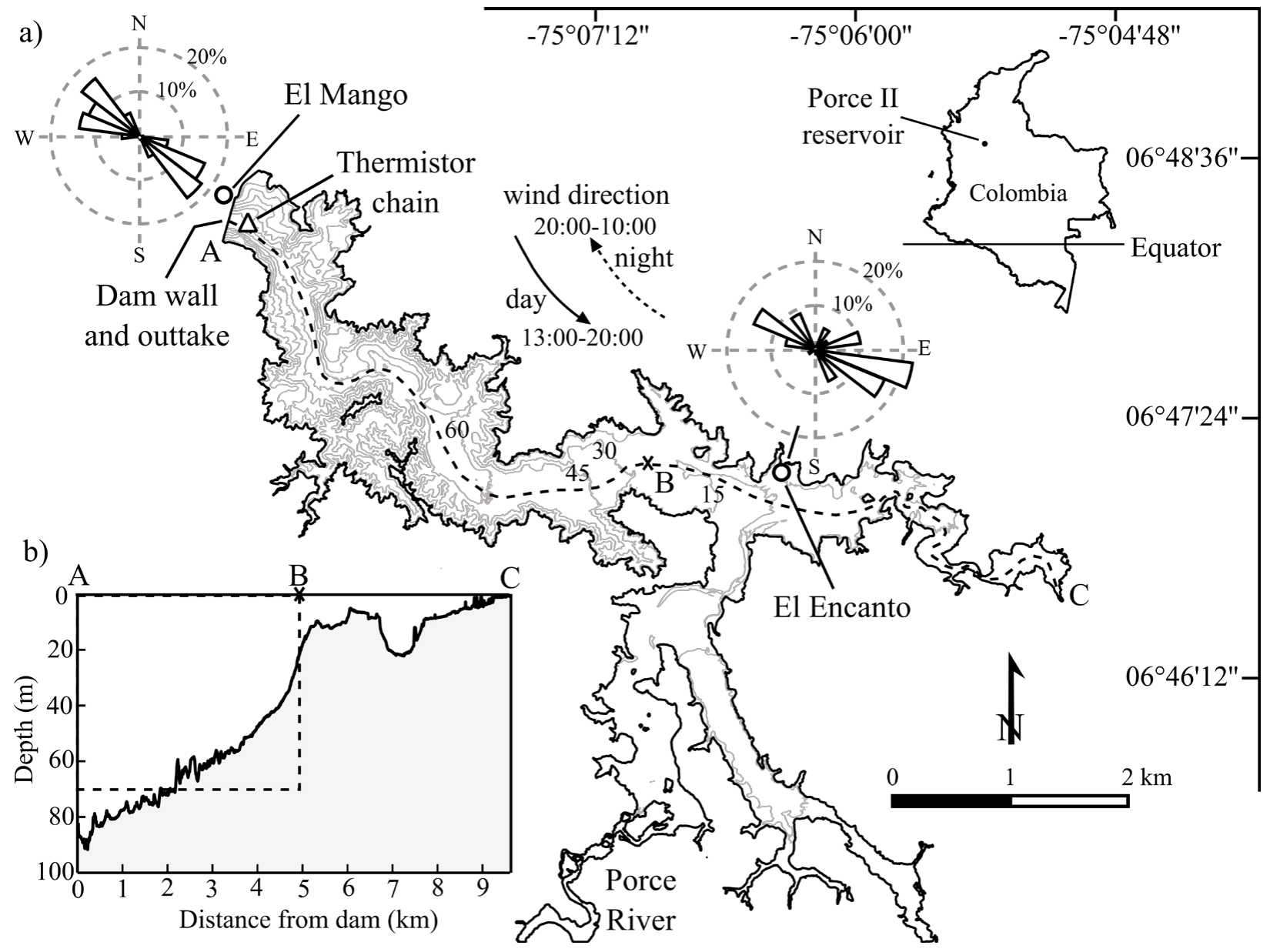

Figure 1. (a) Porce II reservoir location with bathymetry, thermistor chain station (white triangle) and meteorological stations (white circles). Isobaths are shown every $15 \mathrm{~m}$. The wind rose was calculated for wind speeds above $2 \mathrm{~ms}^{-1}$ from measurements during the survey. Inset (b) bottom basin along the thalweg, which is shown as the dashed line in (a). The dashed rectangle in (b) represents the rectangular domain defined to solve the eigenfunction model. 
Field data. One thermistor chain was installed close to the dam around the deepest zone of the reservoir (Figure 1) recording data every $15 \mathrm{~min}$ during the dry period from March 30 to April 08 of 2011. The thermistor mooring was composed of 13 temperature loggers located at depths of 0.5 , $1,2,3,4,6,8,12,22,30,38,40$ and $44 \mathrm{~m}$. The shallow temperature sensors $\left(<30 \mathrm{~m}\right.$ depth) were HOBO Pendant ${ }^{\circledR}$ (ONSET), with an accuracy of $0.53{ }^{\circ} \mathrm{C}$ (resolution of $0.14{ }^{\circ} \mathrm{C}$ ) and the remaining were $\mathrm{HOBO}{ }^{\circledR}$ Pro V2 (ONSET), with an accuracy of $0.2{ }^{\circ} \mathrm{C}$ (resolution of $0.02{ }^{\circ} \mathrm{C}$ ). We measured a conductivity, temperature, and depth (CTD) profile of high vertical resolution (around $20 \mathrm{~cm}$ bin-size) using a SeaBird Scientific CTD during April 05 of 2011 at the same location of the thermistor chain. Wind speed and direction were recorded at the dam site by El Mango meteorological station and with the portable Davis Instruments ${ }^{\circledR}$ Vantage Pro 2 meteorological station at El Encanto site (Figure 1) with sampling intervals of $30 \mathrm{~min}$ and $15 \mathrm{~min}$, respectively. Wind information at El Mango and hydrological records of the Porce River inflow and the outtake discharge were provided by the owner of the reservoir, Empresas Públicas de Medellín, at 30 minutes intervals.

Spectral analysis. Fourier analysis was applied to three types of time series: (i) Isotherm depth time series calculated from the measured temperature field data, (ii) temperature records, and (iii) forcing time series (i.e., wind speed and hydrological discharges). Isotherm depths were calculated by linear interpolation of the thermistor chain temperature data. Power spectral density estimations were calculated from the modified periodogram by averaging in the frequency domain to improve the statistical confidence (Bendat \& Piersol, 1986). The significance of the spectral peaks was tested by comparing the computed spectrum against the mean red noise spectrum from the time series by performing a $\chi_{2}^{2}$-test with a probability of error of $\alpha=0.05$ and a $95 \%$ confidence level and two degrees of freedom (Torrence \& Compo, 1998). The lower confidence boundary for the spectral peaks was defined as the upper 95\% significance level for the red noise signal (a first-order autoregressive process) containing the same variance as the observed time series (Gilman, et al., 1963). In order to identify the vertical structure of the internal waves, we performed cross power spectral analysis and calculated the coherence and phase difference (Bendat \& Piersol, 1986) between pairs of temperature series recorded at different depths.

Numerical model. To describe the baroclinic modes of Porce II, we implemented a model that provides an adequate representation of the weak and continuous stratification of the reservoir assuming a rectangular basin geometry of uniform depth $H$ and length $L$. Starting from the continuity and the momentum equations, neglecting viscous and nonlinear effects, assuming incompressibility, and applying the Boussinesq approximation to the fluids equations of motion, we obtained the following two-dimensional linear wave approximation (Gill, 1982; Münnich, et al., 1992):

$$
\frac{\partial^{2}}{\partial t^{2}}\left(\frac{\partial^{2} w}{\partial z^{2}}+\frac{\partial^{2} w}{\partial x^{2}}\right)+N^{2} \frac{\partial^{2} w}{\partial x^{2}}=0
$$

where

$$
N^{2}=-\frac{g}{\rho} \frac{\partial \rho}{\partial z}
$$

$w$ denotes the vertical velocity component, $z$ is the height measured from the flat bottom basin, $x$ and $y$ are the horizontal coordinates, and $N$ is the Brunt-Väisälä or buoyancy frequency. In the case of internal waves, surface elevations are small, therefore, we used the rigid lid approximation, thus, the boundary conditions were as follows:

$$
w(x, z=H)=w(x, z=0)=0
$$

To obtain the baroclinic modes, we had to find the nontrivial solutions to eq. 1 subject to these boundary conditions. We assumed a periodic time dependence, so $w=\chi(x, z)$ $e^{i \omega t}$, and by taking advantage of the flat bottom geometry, we assumed decoupled solutions in $x$ and $z: \chi(x, z)=\xi(x)$ $W(z)$. By replacing this expression in eq. 1, we obtained two ordinary differential equations in $\xi(x)$ and $W(z)$ :

$$
\begin{gathered}
\frac{d^{2} \xi(x)}{d x^{2}}+C \xi(x)=0 \\
\frac{d^{2} W(z)}{d z^{2}}+C \frac{N^{2}(z)}{\omega^{2}} W(z)=0
\end{gathered}
$$

where $C$ is a separation constant to be determined. The general solution of eq. 4 for $\xi$ was

$$
\xi(x)=A \sin \left(k_{x} x+\phi_{0}\right)
$$

where $k_{x}$ is the horizontal wave number, $A$ is a constant amplitude and $\phi_{0}$ is the phase to be determined from the boundary conditions. Thus, eq. 6 yields the separation constant $C=k_{x}^{2}$. Replacing this constant in eq. 5 we obtained (Gill, 1982)

$$
\frac{d^{2} W_{n}(z)}{d z^{2}}+\frac{N^{2}(z)}{c_{n}^{2}} W_{n}(z)=0
$$

where $c_{n}$ is the horizontal phase speed and $W_{n}$ is the vertical structure of the $n^{\text {th }}$ vertical mode. This is of the SturmLiouville form, which is analogous to the normal modes of oscillations of other systems, e.g., the stretched string. For a continuously stratified lake, there is an infinite set of possible values (eigenvalues):

$$
c_{n}, \quad n=1,2,3, \ldots,
$$

associated with the corresponding eigenfunctions, the normal modes:

$$
W_{n}(z), \quad n=1,2,3, \ldots,
$$

that satisfy eq. 7. Although eq. 7 describes all the vertical wave modes along an infinite $x$-axis, we are only interested in the standing waves, whose wavelength $\left(\frac{2 \pi}{k_{x}}\right)$ must be an integer part of twice the length of the lake, $2 L$. Hence, for those standing waves,

$$
k_{m}=m \frac{\pi}{L}, \quad m=1,2,3, \ldots,
$$

where $m$ is the horizontal order of the mode. Thus, for every $c_{n}$ obeying eq. 7 there must exist a set of certain frequencies $\omega_{m n}$ (the eigenfrequencies) associated with the horizontal 
wavelengths $k_{m}$ determined by solving eq. 10 that represent the baroclinic modes of the basin. In that way, the natural frequencies and periods $T_{m n}$ of the baroclinic modes are

$$
\omega_{m n}=c_{n} k_{m}, \quad T_{m n}=\frac{2 \pi}{\omega_{m n}}, \quad n=1,2,3, \ldots, \quad m=1,2,3, . .,
$$

To solve the eq. 7 for the vertical structure and phase velocity of the modes, the $z$-axis was discretized using centered finite differences, which, along with the boundary conditions, led to a matrix formulation with the generalized eigenvalue form:

$$
\boldsymbol{A} \Phi=\lambda \boldsymbol{B} \Phi
$$

where $\boldsymbol{A}$ is a matrix determined by the discretization on the $z$-axis, $\boldsymbol{B}$ a matrix determined by the discretized buoyancy frequency in the $z$-axis and $\lambda$ is the eigenvalue related to the wave phase velocity as $\lambda=1 / c_{\mathrm{n}}^{2}$. For a uniform vertical discretization of the water column $(\Delta z)$, the squared matrices $\boldsymbol{A}$ and $\boldsymbol{B}$ are:

$$
\begin{gathered}
\boldsymbol{A}=\left[\begin{array}{cccccc}
2 / \Delta z^{2} & -1 / \Delta z^{2} & 0 & 0 & \ldots & 0 \\
-1 / \Delta z^{2} & 2 / \Delta z^{2} & -1 / \Delta z^{2} & 0 & \ldots & 0 \\
0 & -1 / \Delta z^{2} & 2 / \Delta z^{2} & -1 / \Delta z^{2} & \ldots & 0 \\
0 & 0 & -1 / \Delta z^{2} & 2 / \Delta z^{2} & \ldots & 0 \\
\vdots & \vdots & \vdots & \vdots & \ddots & -1 / \Delta z^{2} \\
0 & 0 & 0 & 0 & -1 / \Delta z^{2} & 2 / \Delta z^{2}
\end{array}\right] \\
\boldsymbol{B}=\left[\begin{array}{cccccc}
N_{1}{ }^{2} & 0 & 0 & 0 & \ldots & 0 \\
0 & N_{2}{ }^{2} & 0 & 0 & \ldots & 0 \\
0 & 0 & N_{3}{ }^{2} & 0 & \ldots & 0 \\
0 & 0 & 0 & N_{4}{ }^{2} & \ldots & 0 \\
\vdots & \vdots & \vdots & \vdots & \ddots & 0 \\
0 & 0 & 0 & 0 & 0 & N_{k}^{2}
\end{array}\right]
\end{gathered}
$$

where the subscript $k$ indicates the position in the vertical grid and $N_{k}$ is the corresponding buoyancy frequency of the $k$-th cell.

The vertical velocities obtained by the model have arbitrary units because the resultant eigenvectors are not realistic velocity vectors. Thus, the vertical displacement, $\delta$ $=w / i \omega$, which differs from the vertical velocity $w$ only by one factor $(1 / i \omega)$, has the same vertical structure to that of the vertical velocity (Fricker \& Nepf, 2000). Finally, the horizontal velocity component in the middle of the reservoir associated to the baroclinic modes was calculated from the vertical velocity at one end of the basin by integrating the two-dimensional continuity equation (Münnich, et al., 1992).

\section{Results}

Thermal structure, hydrology and wind forcing. Diurnal wind speeds occurred regularly over the reservoir, with maximum speeds between the 13:00 $\mathrm{h}$ and 20:00 hours coming mainly from the northwest, ascending from the dam and through the river canyon. Lower wind speeds occurred during the night and early morning with an opposite wind direction along the canyon valley towards the dam site (Figure 2a). The power spectrum of the wind speed measured at both stations showed the dominant $24 \mathrm{~h}$ periodicity of the wind-forcing (Figure 3a) with a minor peak around the
$12 \mathrm{~h}$ period. Diurnal cycles of atmospheric pressure above the reservoir were related to the diurnal cycle of the wind forcing (not shown). However, given the spatial scale of the reservoir, it is very unlikely that the horizontal gradients of atmospheric pressure become high enough to excite internal wave motions and for that reason, this variable was not included in the subsequent analyses.

Low inflow discharges dominated during the field campaign, with a gradual increase throughout the survey and the occasional arrival of important discharges towards the end of the period. Outflow discharges occurred with a variable operation, with similar magnitudes to those of the inflows when the outtake was in operation. A dominant frequency component in the inflows and outflows time series was not identified, as can be seen from their power spectra (Figures 3b,c).

The evolution of the thermal structure showed a gradual deepening of the isotherms between depths of 10 and 30 meters, which indicates a warming of these waters due to the surface heat fluxes. Towards the end of the survey (from April 6 onwards), there was a change in the deepening rate of the isotherms, with a faster deepening for the isotherms

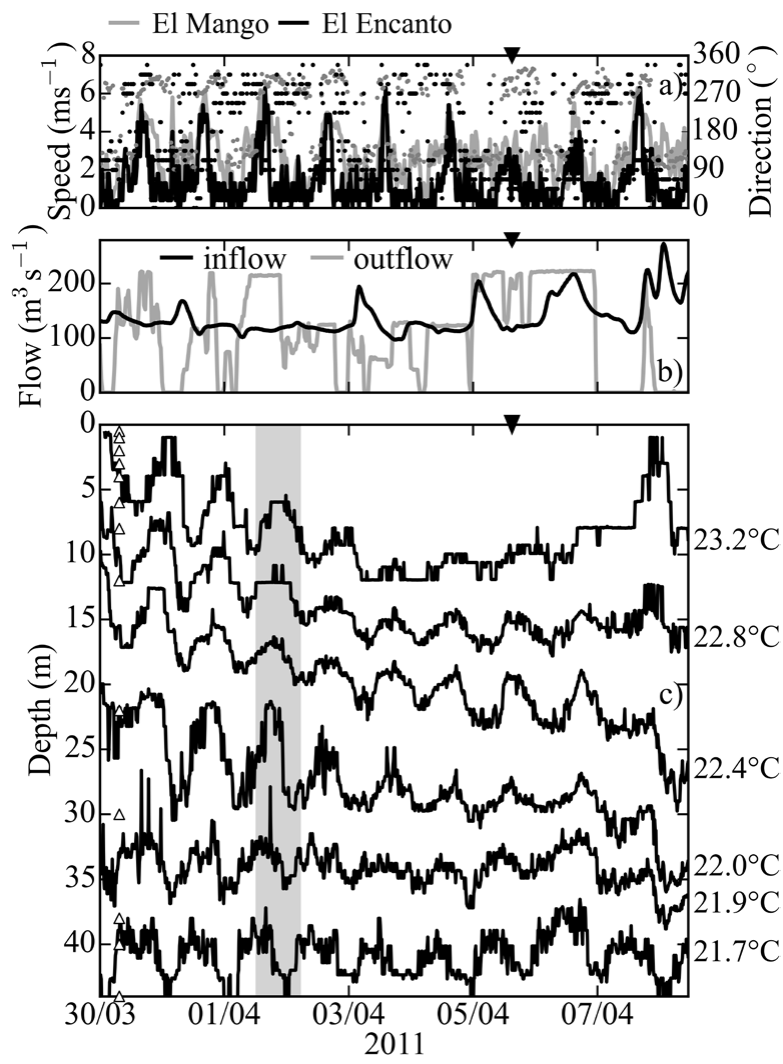

Figure 2. (a) Wind speed (line) and direction (dots), (b) inflow and outflow discharges, and (c) isotherm displacements. The black triangle at the top of the panels marks the time of measurement of a temperature profile with the CTD. Triangles in panel (c) mark the depths of the thermistors. The gray shadowed area in panel (c) indicates the period discussed in the text. 

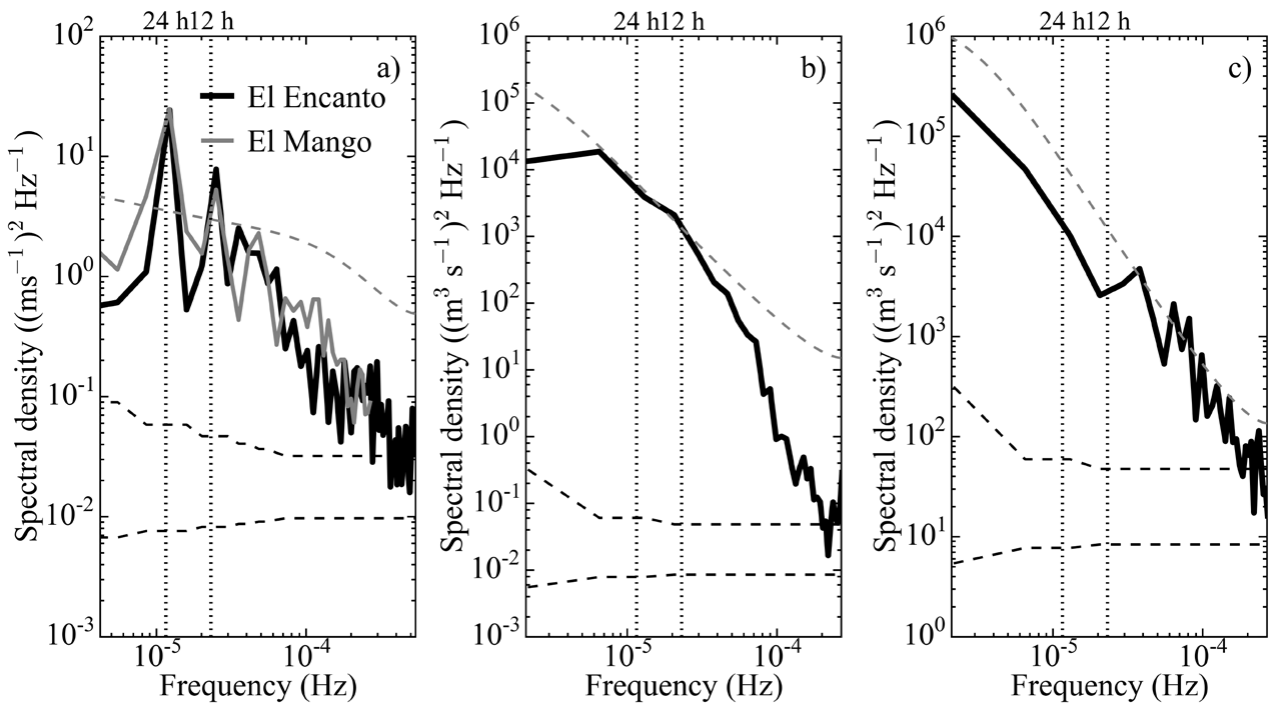

Figure 3. Power spectrum of (a) wind speed, (b) inflow discharge, and (c) outflow discharge. The dashed gray lines indicate the significance limit for the spectral peaks with a confidence level of 95\% (Torrence $\&$ Compo, 1998). The bottom dashed black lines indicate the confidence bands of the power spectra with a confidence of $95 \%$. The vertical dotted lines mark the $12 \mathrm{~h}$ - and $24 \mathrm{~h}$-periods.

below $20 \mathrm{~m}$ deep and an upward trend in the isotherms above $20 \mathrm{~m}$ (Figure 2c). According to the observations by Gómez-Giraldo, et al. (2012), this behavior is a typical signature of the effect of the Porce River plume on the thermal structure during dry periods.

Two features of the dynamics of the isotherm displacements stand out. First, there was a dominant periodicity close to $24 \mathrm{~h}$ in the vertical displacements that gradually reduced its amplitude towards the end of the survey. Second, the top and bottom isotherms shown in Figure 2c oscillated against one other indicating a corresponding oscillation in the thickness of the middle layers of the reservoir. For instance, during April 1 (see the gray panel in Figure 2c), the displacement of upper isotherm $\left(23.2^{\circ} \mathrm{C}\right)$ was upward while the displacement of the bottom isotherm $\left(21.7^{\circ} \mathrm{C}\right)$ was downward.

Observed internal waves. The isotherm displacements and their associated power spectra exhibited a dominant and statistically significant energy peak around the 24-h period (Figure 4), as expected from the qualitative analysis of Figure 2, and matching the major peak in the wind speed power spectrum. The amplitude, and hence the energy, of the internal wave oscillations, gradually decreased throughout the survey period, reaching minimum energy towards the end of it.

To identify the nature of the 24-h period oscillations, we calculated the coherence and phase spectra between the temperatures recorded by the thermistors at $6 \mathrm{~m}$ and at $20 \mathrm{~m}$ and between thermistors at $6 \mathrm{~m}$ and at $44 \mathrm{~m}$ (Figure 5a,b). For the 24-h period, the coherence was high and statistically significant for both pairs of temperature records. The phase spectra around this period provided information about the vertical structure of the oscillations. Around the 24-h period
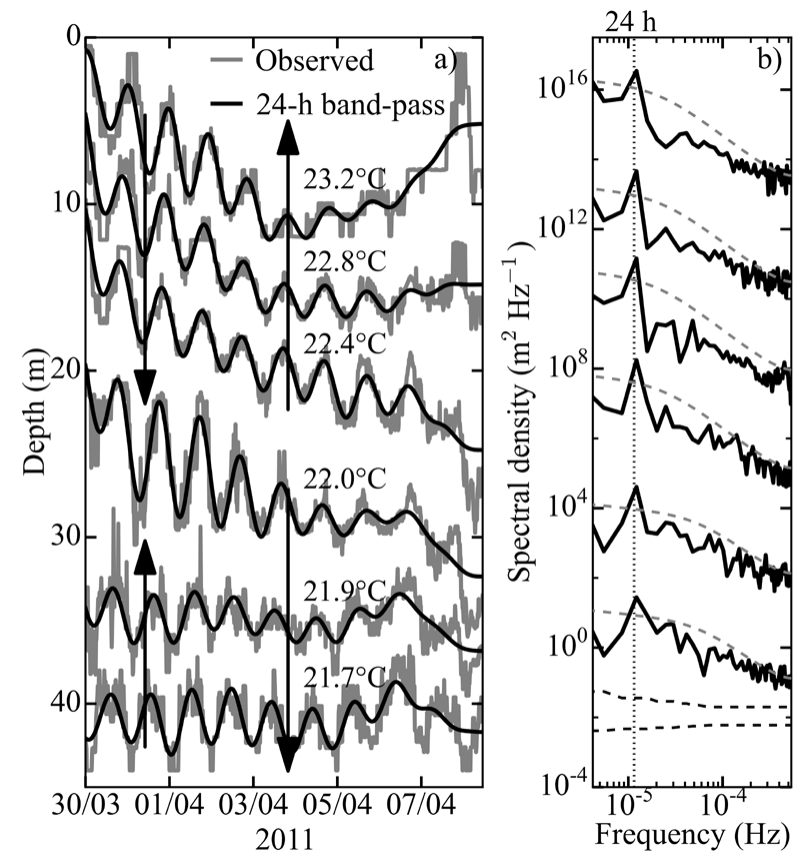

Figure 4. (a) Depth time series of isotherms and its band-passed signal around the 24-h period band. The arrows make explicit the direction of the vertical displacements. (b) Power spectra of isotherm displacement. The dashed gray lines indicate the significance limit for the spectral peaks with a confidence level of 95\% (Torrence \& Compo, 1998). The bottom dashed black lines indicate the confidence bands of the power spectra with a confidence of $95 \%$. Offset between spectra is three logarithmic cycles. The vertical dotted line marks the 24 h-period.

band, the $6 \mathrm{~m}$ and $44 \mathrm{~m}$ temperature records oscillated out of phase with one another while the temperatures at $6 \mathrm{~m}$ and $12 \mathrm{~m}$ oscillated in phase (Figure 5a,b). 
To improve the understanding of the vertical structure of the oscillations, we calculated the coherence and phase for the $24 \mathrm{~h}$ period between the temperature at every thermistor depth and the temperature at $6 \mathrm{~m}$ depth, defined arbitrarily as reference. Figure $5 \mathrm{c}$ shows the vertical structure of the

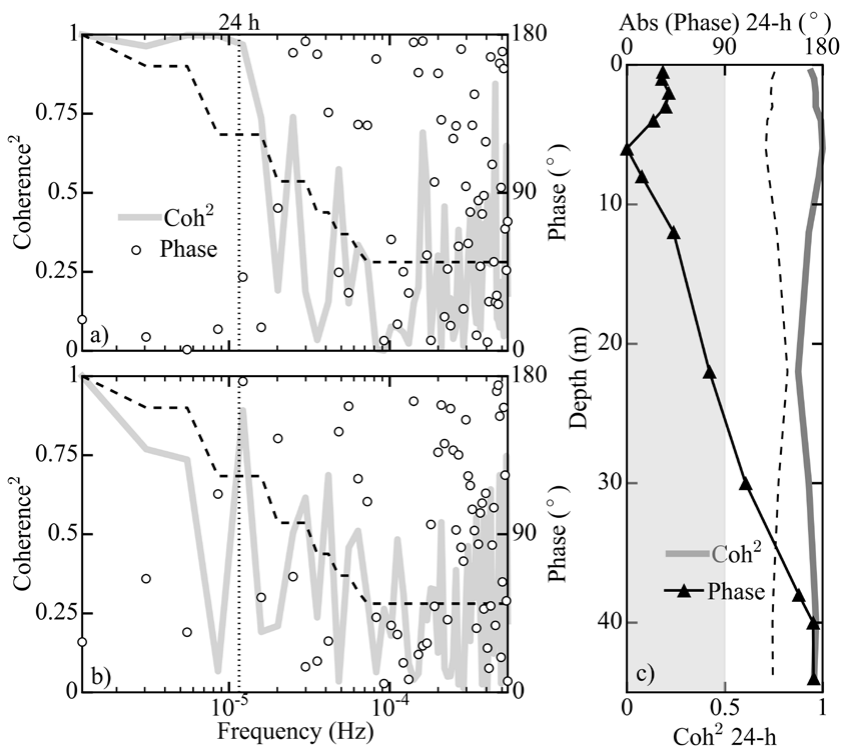

Figure 5. Coherence and phase spectra between temperature time series at (a) $6 \mathrm{~m}$ and $12 \mathrm{~m}$ deep and (b) at $6 \mathrm{~m}$ and $44 \mathrm{~m}$ deep. (c) Vertical profile of coherence and phase for the 24 -h period band using the temperature series at $6 \mathrm{~m}$ depth as reference. The black dashed line in all panels indicates the threshold of $95 \%$ significance for the coherence. coherence and phase for the 24-h period oscillations. The vertical-two structure o the oscillations can be confirmed in the depth range covered by the thermistor chain with a change of phase around 20 to $30 \mathrm{~m}$ deep.

Thus, the 24-h peak of the isotherms displacements was associated with a second vertical mode or higher. However, at this point it is not possible to establish with certainty the vertical order of the mode from the field data, as the thermistor chain did not cover the whole depth range of the reservoir and, hence, it could be possible that below 44 $\mathrm{m}$ (the location of the deepest thermistor) another change of phase occurs. It should be noted that our data does not strictly exhibit phase differences of $0^{\circ}$ or $\pm 180^{\circ}$, which would be expected for pure modes. The discussion of this result is presented below.

Predicted baroclinic modes by the eigenmodel. We set the uniform depth of the domain at $70 \mathrm{~m}$ and $5 \mathrm{~km}$ length, which is the approximated length of the main body of the reservoir where the basin-scale oscillations are expected to occur (Figure 1b). Since the thermistor chain covered only the first $44 \mathrm{~m}$ of the water column, the buoyancy frequency required to solve the model was calculated from the temperature profile measured with the CTD, which covered all the water column and shows a similar structure to the average temperature profile measured with the thermistor chain for the survey (Figure 6a). In addition, the CTD profile was smoothed using a fourth-order Butterworth filter, as the results of the eigenfunction model are not significantly sensitive to the small-scale features of the stratification profile (Münnich, 1996).
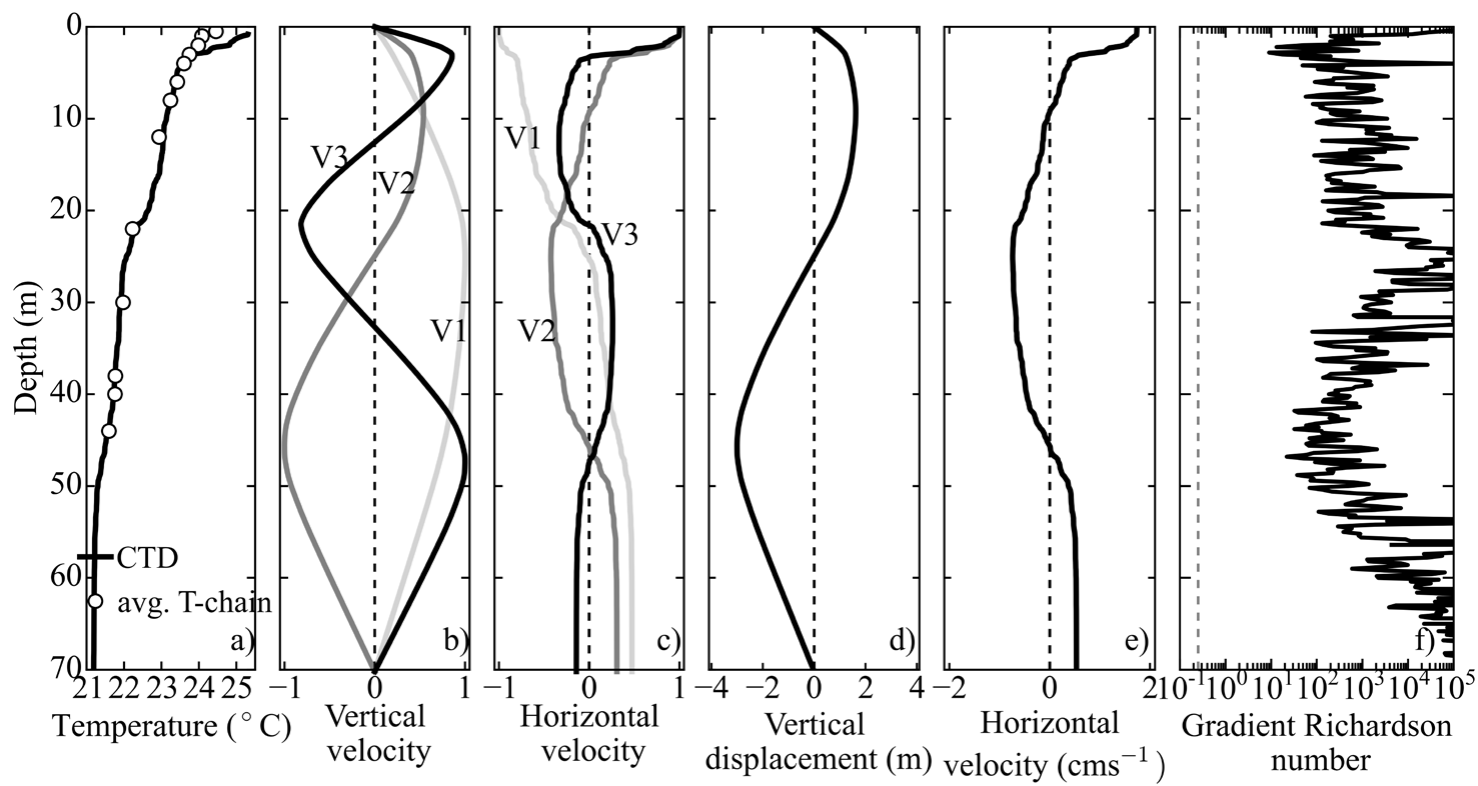

Figure 6. (a) Average temperature profile of the thermistor chain for the survey (dots) and the temperature profile measured with the CTD (line); (b) vertical and (c) horizontal velocity profiles associated with the lowest three baroclinic natural modes. (d) Vertical isotherm displacement profile scaled for a maximum amplitude of $3 \mathrm{~m}$ and its (e) associated horizontal velocity profile for the V2H1 mode. (f) Gradient Richardson number associated with the V2H1 baroclinic mode. The dashed line in (f) indicates the critical value of 0.25 . 
The vertical structure of the first three natural modes predicted by the eigenmodel is shown in Figures $6 b, c$. The natural periods (phase velocities) associated with the lower vertical modes V1, V2, and V3 are $12.7 \mathrm{~h}\left(0.22 \mathrm{~ms}^{-1}\right), 25.2 \mathrm{~h}$ $\left(0.11 \mathrm{~ms}^{-1}\right)$, and $35.2 \mathrm{~h}\left(0.09 \mathrm{~ms}^{-1}\right)$, respectively.

\section{Discussion}

Porce II as a wind-forced damped oscillator. The combined analysis of the field data and the results of the eigenmodel indicated that during the survey, a V2H1 mode of natural period close to $24 \mathrm{~h}$ was excited in the reservoir and the depth of change of phase of the oscillations occurred between 20 and $30 \mathrm{~m}$ deep. The spectral analysis of the wind speed showed a significant secondary peak around the 12-h period, which matched the theoretical period of the V1H1 mode predicted by the eigenmodel. However, the measured isotherm displacement did not show any significant energy content around that period, which indicates that the mode was not excited during the survey. Although the simultaneous response of several modes is not a rare feature (Antenucci, et al., 2000; Vidal, et al., 2007), this was not observed in Porce II and the V2H1 mode was the only dominant seiche. A possible aspect inhibiting the excitation of the V1H1 mode is that, although a 12 -h periodic onset of the wind exists, its duration is less than one-quarter of the mode period (i.e., $\sim 3 \mathrm{~h}$ ), which is the minimum duration of a wind event leading to the formation of the horizontal baroclinic gradients (Spigel \& Imberger, 1980) necessary for the complete excitation of the mode. On the other hand, it has been shown that when internal waves are excited by density currents there is a strong influence of the level of neutral buoyancy of the currents on the relative proportion of energy transferred to the different vertical wave modes (Maurer \& Linden, 2014). Although more research is needed to prove it, we suggest that the inhibition of the V1 mode excitation is caused by the currents from the selective withdrawal and the river plume moving between $10 \mathrm{~m}$ and $40 \mathrm{~m}$, which is the depth range on what the V1 mode should change the velocity direction (Figure 6d). Such depth range coincided with the middle layer of the V2 mode (Figure 6d), so the currents did not interfere with the horizontal motion of the V2 mode.

Previous studies have shown that the periodic operation of the outflow discharge in a reservoir may lead to the excitation of internal waves (Imberger \& Fandry, 1975; Ibarra, et al., 2015). It has also been shown that internal waves may be energized by the intrusion of density currents in stratified environments (Maxworthy, et al., 2002; Nash \& Moum, 2005). According to the spectral analysis, it can be concluded that the wind is the only forcing whose spectral content explains the baroclinic oscillations occurring in Porce II reservoir. Thus, it is possible to affirm that the V2H1 baroclinic mode was excited by resonance with the wind forcing. This dynamic regime has been observed in other stratified lakes, such as Lake Alpnach (Münnich, et al., 1992; Lorrai, et al., 2011).
To get a deeper insight into the link of the water column response and the wind-forcing, we assimilated the reservoir to a harmonic, viscously damped wind-forced oscillator. We 24-h bandpass-filtered the observed oscillations of the $25 \mathrm{~m}$ depth isotherm and adjusted the output to the oscillation of a linear damped forced mass-spring system (Gómez-Giraldo, et al., 2006). This simple dynamic system allows the description of the oscillations of the reservoir without including the complexities added by the spatial structure (Stocker \& Imberger, 2003). The wind forcing, $F$, was discretized by 15 -min long uniform wind blocks. Each constant wind block was considered as made up of a suddenly imposed steady wind event of infinite duration and an equal but negative wind starting 15 min later. At a particular location in the reservoir, the isotherm oscillation generated by every suddenly imposed steady wind event (positive or negative) of infinite duration is given by

$$
\begin{gathered}
x_{i}(t)=A F_{i}\left\{1-\cos \left[\omega\left(t-t_{\text {lag }}\right)\right] e^{-\alpha\left(t-t_{\text {lag }}\right)}\right\} H(t) \\
\zeta=\frac{\alpha}{\omega_{0}} \quad \omega^{2}=\omega_{0}^{2}-\alpha^{2}
\end{gathered}
$$

where $x$ is the displacement from the equilibrium position, $t$ is the elapsed time from the start of the wind event, the coefficient $A$ and the phase $t_{\text {lag }}$ account for the spatial location and $H$ is the unit step function, the parameter $\alpha$ is the inverse of the $e$-folding time, which is given by $T_{d}=T(2 \pi \zeta)^{-1}$, the damping ratio $\zeta$ is the ratio of the decay constant $\alpha$ to the undamped natural frequency $\omega_{0}, T$ is the natural period, and $\omega$ is the damped natural frequency of the system. The displacement generated by the wind speed time series is given by the linear superposition of the displacements generated by each individual wind-block (positive and negative):

$$
X\left(t, \alpha, \omega, A, t_{\text {lag }}\right)=\sum_{i=1}^{M} x_{i}\left(t-t_{s i}\right)
$$

where $t_{s i}$ is the time of the start of the $i$ th wind event and $M$ is the total number of positive and negative wind events. The values of $\alpha, \omega, A$, and $t_{\text {lag }}$ were obtained by leastsquared fitting $X$ with the 24-h bandpass-filtered isotherm displacement.

Figure 7 shows the adjustment obtained with a good fit between the model and the measured vertical displacement. Towards the end of the period, a reduction in the amplitude of the 24-h period oscillation seems to be associated with the decay of the 24-h component of the wind forcing.

The damping ratio obtained for the V2H1 mode was compared to damping ratios of seiche modes in other lakes around the globe (Table 1). The damping ratio of the V2H1 mode in Porce II $(\zeta=0.08)$ is well below the critical damping $\left(\zeta_{c}=1\right)$, so the oscillations were underdamped, which has also been observed in most stratified systems with few cases (Imam, et al., 2013) reporting overdamped oscillations. We observed that the damping ratio and the $e$-folding time of the V2H1 mode in Porce II were similar to that reported in the other lakes in spite of the differences in size, geographical location, stratification intensity, and vertical structure. We 
have speculated that the major source of damping of the baroclinic motions in the reservoir is the bottom friction, as the turbulence at the interior due to the internal wave currents seems to produce low turbulence activity, as we discuss below.

Potential diapycnal mixing induced by the baroclinic modes. We carried out a scaling analysis to evaluate the potential for diapycnal mixing induced by the baroclinic modes in Porce II. Following Miles (1961), we calculated the gradient Richardson number given by

$$
R i=\frac{N^{2}}{(\partial u / \partial z)^{2}}
$$

which expresses the ratio of the stability due to the stratification (given by $N$ ) and the destabilization induced by the shear $(\partial u / \partial z)$. If $R i$ is smaller than a critical value of 0.25 , the water column may become unstable and vertical mixing can be generated through Kelvin-Helmholtz instabilities.

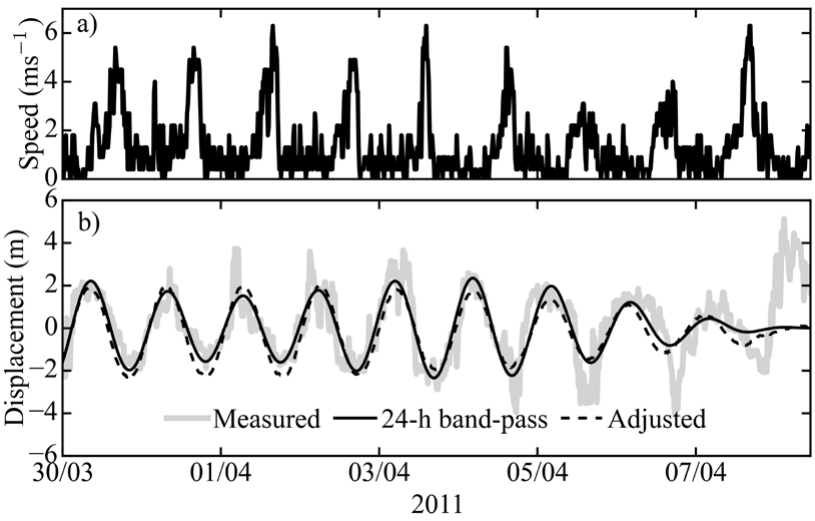

Figure 7. (a) Wind speed. (b) $25 \mathrm{~m}$-depth isotherm vertical displacement measured and detrended, 24-h bandpass-filtered and estimated by the mechanical model.
The vertical displacements predicted by the eigenmodel were scaled by a maximum amplitude of $3 \mathrm{~m}$ (Figure 6d), which was defined from the observed isotherm oscillations (Figure 2c) while the horizontal velocity component was calculated from the vertical velocity by integrating the twodimensional continuity equation (Münnich, et al., 1992). Figure 6 shows how $R i$ is higher than 0.25 all along the water column, which indicates that mixing-inducing instabilities were not produced at the interior of the water column by the baroclinic mode. Thus, we suggest that a turbulent bottom boundary layer driven by the seiche-associated currents was the major source of mixing, dissipation, and damping of the basin-scale oscillations. In sloping bottom basins as Porce II, basin-scale circulations associated with the internal waves can accelerate the flow close to the boundaries and favor the formation of supercritical shear layers, which, in turn, induce mixing around the metalimnetic region that intersects the lake boundary (Ulloa, et $\boldsymbol{a l}$. , 2018). Direct measurements of turbulent dissipation (Román-Botero, et al., 2017) also showed that during periods of dominant basin-scale internal waves activity in Porce II, there was a strongly stratified turbulence at the interior (far from the boundaries), characteristic of low dissipation, in contrast with the high-isotropic turbulence induced by the density plumes during flood events.

Potential implications for reservoir ecology. It has been shown that internal wave oscillations may affect the water quality withdrawn from a reservoir because the vertical fluctuations induced by the standing waves expose different water masses to the selective withdrawal at the forefront of the intake gates (Figure 2S-a1, https://www.raccefyn.co/ index.php/raccefyn/article/downloadSuppFile/799/3896; 2S-a2, https://www.raccefyn.co/index.php/raccefyn/article/ downloadSuppFile/799/3896) (Anohin, et al., 2006). In

Table 1. Damping in selected lakes. Modified from Imam, et al. (2013).

\begin{tabular}{|c|c|c|c|c|c|}
\hline Lake & $\begin{array}{l}\text { Length h } \\
\quad(\mathbf{k m})\end{array}$ & $\begin{array}{l}\text { Mode period, } \\
\qquad T(d)\end{array}$ & $\begin{array}{l}\text { Damping time } \\
\text { scale, } T_{d}(\mathrm{~d})\end{array}$ & $\begin{array}{l}\text { Damping } \\
\text { ratio, } \zeta\end{array}$ & Source \\
\hline Baldegg Lake & 4.5 & $0.3-0.4$ & $>7$ & $<0.009$ & Lemmin (1987) \\
\hline Wood Lake & 7 & 0.5 & 2.0 & 0.04 & Wiegand \& Chamberlain (1987) \\
\hline \multirow{2}{*}{$\begin{array}{l}\text { North basin of } \\
\text { Windermere }\end{array}$} & \multirow[t]{2}{*}{7} & 0.8 & 3.1 & 0.04 & \multirow{2}{*}{$\begin{array}{l}\text { Mortimer (1952); Heaps \& Ramsbottom } \\
\text { (1966); Spigel \& Imberger (1980) }\end{array}$} \\
\hline & & $0.5-0.6$ & $2.0-2.3$ & 0.04 & \\
\hline Sooke Lake Reservoir & 4 & 0.3 & 0.7 & 0.07 & Stevens (1999) \\
\hline Lake Tiberias & 22 & 0.9 & 1.8 & 0.08 & Shimizu \& Imberger (2008) \\
\hline Untersee (Lake Zurich) & 29 & 1.8 & 2.1 & 0.14 & Horn, et al. (1986) \\
\hline \multirow[t]{2}{*}{ Kootenay Lake } & \multirow[t]{2}{*}{100} & 5 & 5.7 & 0.14 & Stevens, et al. (1996) \\
\hline & & 12 & 10.6 & 0.18 & \\
\hline Nechako Reservoir & 75.6 & 5.7 & 0.8 & 1.2 & Imam, et al. (2013) \\
\hline Lake Villarrica & 20 & 0.9 & 30.0 & 0.03 & Rozas, et al. (2014) \\
\hline Porce II Reservoir* & 10.0 & 1.1 & 1.9 & 0.08 & \\
\hline
\end{tabular}

*Results from the present work 
Porce II, the vertical oscillations of up to $4 \mathrm{~m}$ at the depth of the submerged gates could be important for inducing essential changes in the quality of the water withdrawn, which in turn may be important for the quality of the river and Porce III reservoir located downstream of Porce II dam. The dominant V2H1 mode during the survey has the peculiarity of generating a periodic contraction and expansion of the middle layers of the reservoir (Münnich, et al., 1992). The horizontal pressure gradient generated by that periodic variation in the thickness of the layers can favor the transit towards the dam site of the masses of water inserted at mid-depths by the river plume (Figure 2Sb1, https://www.raccefyn.co/index.php/raccefyn/article/ downloadSuppFile/799/3896; 2S-b2, https://www.raccefyn. co/index.php/raccefyn/article/downloadSuppFile/799/3896) (Vidal, et al., 2007). In this way, it can decrease the transit time of the river plume into the system and, hence, influence the retention time of the water, which is a very important parameter for water quality (Soares, et al., 2008). On the other hand, the amplitude of internal waves can be sufficient to define the intrusion depth of a river plume depending on the phase of the oscillations and the background conditions that face the plume when it enters the reservoir (Figure 2Sc1, https://www.raccefyn.co/index.php/raccefyn/article/ downloadSuppFile/799/3896; 2s-c2, https://www.raccefyn. co/index.php/raccefyn/article/downloadSuppFile/799/3896) (e.g. Cortés, et al., 2014; Hogg, et al., 2018). Our calculations suggest that the seiche-associated currents induce weak diapycnal mixing at the interior of the water column. Thus, it is suggested that a turbulent bottom boundary layer driven by seiche currents is the major source of the internal wave dissipation, possibly inducing resuspension of sediment and other substances (Wiegand \& Chamberlain, 1987). It should be noted that the aforementioned mechanisms of interaction of the natural modes and the water quality are only hypothetical scenarios and none of them has been proved in this work. However, they are described here to highlight the importance of studying internal waves and their linkage to the water quality of stratified inland waters.

River intrusions incorporate nutrients into the upper mixed layer where important primary productivity occurs by the turbulent mixing and advection which are moduled by other physical processes (MacIntyre, 1993; MacIntyre \& Jellison, 2001; Cortés, et al., 2014). During the dry season in Porce II, typical inflow plumes loaded with nutrients intrude at depths of 20 to $30 \mathrm{~m}$ (Gómez-Giraldo, et al., 2012). We performed a simple decoupled analysis of the time scale that internal waves induced turbulent mixing takes to transport nutrients vertically from the river intrusion to the upper mixed layer. For this analysis, we neglected the contribution of the density current and other processes in vertical turbulent mixing as they evolve. The time scale for the turbulent diffusive transport $\left(\tau_{m i x}\right)$ of substances from the plume up to the surface layer is $\tau_{m i x} \sim \frac{\ell^{2}}{K_{z}}$, where $K_{z}$ is the eddy vertical diffusivity and $\ell$ is the length scale. To incorporate the load of nutrients introduced by the river plume into the surface layer would require a vertical distance $\ell \sim 20 \mathrm{~m}$. According to the magnitudes estimated of $R i>>1$ all along the water column and the $K_{z}$ parameterization as a function of $R i$ (Yeates, et al., 2013), the eddy vertical diffusivity $K_{z}$ at the interior of the water column is of the order of the molecular diffusivity. We assumed a value of $K_{z}=1 \times 10^{-6} \mathrm{~m}^{2} / \mathrm{s}$ (Gloor, et al., 2000), getting $\tau_{m i x} \sim 12$ years. Thus, we suggest that for the typical dry conditions in Porce II reservoir, the diapycnal mixing induced by the internal waves is negligible and other mechanisms and interactions among processes must be responsible for the major vertical transport and mixing at the lake interior.

Vertical structure of the phase. The gradual vertical variation of the phase of the measured temperature from the surface to $40 \mathrm{~m}$ deep (Figure 6c) is not explained by the theory of normal baroclinic modes, which predicts phase shifts of $180^{\circ}$. A similar pattern in the vertical structure of the phase for both measured temperature and velocity has been found in other lakes with a wide metalimnion that matches the depth range where the phase is variable (LaZerte, 1980; Pérez-Losada, et al., 2003; Vidal, et al., 2008; Hingsamer, et al., 2014). In agreement with these authors, we consider that this is the signature of the basinscale internal waves in lakes with a wide metalimnion. According to the wave ray theory (Maas \& Lam, 1995), the baroclinic modes are standing waves that result from the superposition of internal wave rays whose paths close upon themselves after bouncing in the boundaries of the basin (Cushman-Roisin, et al., 1989; Maas \& Lam, 1995; Gómez-Giraldo, et al., 2006). We believe that the sharp phase shifts predicted by the eigenfunction models for flat horizontal bottoms are only possible if there is a complete vertical and horizontal symmetry of the domain. Due to the variations in the slope, depth, and stratification, the direction of the wave ray propagation on a real lake changes with depth and horizontal location. We consider that this makes possible that the rays close upon themselves at a different phase in a vertical profile, especially in the metalimnion, where they are changing direction continuously with the vertical change in the buoyancy frequency. This is likely more visible as the metalimnion thickness to the total depth is larger.

According to Henderson \& Deemer (2012), the gradual variation of the phase in temperature and velocity is the signature of vertical wave propagation and not of standing waves, similar to lee waves formation in stratified systems. They suggest that because of the energy loss at the bottom of the lake, wave rays reflected from the bottom are less energetic than those downward-propagating incident rays. Thus, the superposition of both results in net downward energy propagation. Even if this were the case, it does not explain why the gradual shift in phase is observed in thick metalimnions and is not in very homogeneous hypolimnions and epilimnions. Damping (energy loss) has been recognized as a universal feature observed in basin-scale internal waves 
around the globe (Mortimer, 1952; Heaps \& Ramsbottom, 1966; Wiegand \& Chamberlain, 1987; Shimizu, et al., 2008) in several lakes where the gradual variation in phase is not observed. Our estimated damping rate was similar to those reported from other lakes where standing waves have been identified with a sharper vertical change of phase, so we do not see the attenuation of the downward rays as the cause of the gradual phase shift as suggested by Henderson \& Deemer (2012). However, we recognize that more work is necessary to clarify the nature of gradual vertical phase shift.

Future calculations of the baroclinic modes. It must be recognized that the sloping bottom of the reservoir basin, clearly different from a rectangular basin, can induce phenomena as wave-ray focusing and defocusing which may affect the periods and spatial structures of the internal wave modes (Cushman-Roisin, et al., 1989; Maas \& Lam, 1995; Fricker \& Nepf, 2000; Gómez-Giraldo, et al., 2006). Those effects cannot be captured by the numerical model implemented in this work, which assumes a rectangular flatbottom basin. Nonetheless, as a first approximation to the description of the natural modes, the model provided a good and valuable description of the dominant baroclinic mode observed in the field during the survey analyzed, capturing quite well the natural period and the approximated depth of change of phase of the vertical displacements.

More complete models should be used to capture the properties of the wave field in Porce II taking into account both real bathymetry and stratification. The weak and continuous stratification of Porce II, very different from the typically layered-like summer stratification of temperate lakes, as well as the non-simple morphometry of the reservoir, lead us to suggest that future analysis on the baroclinic modes must be addressed by using more elaborated models than the one used in this work.

\section{Supplementary information}

Figure 1S. Schematic view of the structure of various internal wave modes for a rectangular basin of depth $\mathrm{H}$ and length $\mathrm{L}$ with uniform stratification. The solid lines with arrows indicate the amplitude of the periodic circulation pattern. The dashed line represents the associated amplitude of the isotherms vertical displacement. See the figure $1 \mathrm{~S}$ in: https://www.raccefyn.co/index.php/raccefyn/ article/downloadSuppFile/799/3895

Figure 2S. Schematic view of hypothetical mechanisms that could link basin-scale internal waves and water quality in Porce II reservoir. (a1,a2) Difference of the physical and chemical properties of the mass of water extracted by the selective withdrawal during the two states of maximum vertical displacement associated with the V2H1 mode. (b1,b2) Difference in the advance of the river plume front during the evolution of the two states of maximum vertical displacement associated with the V2H1 mode. (c1,c2) Difference on the neutral buoyancy intrusion depth of the river plume for the two states of maximum vertical displacement associated with the V2H1 mode. See the figure $2 \mathrm{~S}$ in: https://www.raccefyn.co/index. php/raccefyn/article/downloadSuppFile/799/3896

\section{Conclusions}

Internal waves were a prominent feature of the basin-scale hydrodynamics of Porce II reservoir during the dry period studied. An underdamped V2H1 mode was excited in the reservoir by resonance with the diurnal wind forcing and prevailed for several days according to the field observations and the results of a simplified eigenvalue model.

Despite the simplifications involved in the simple model, it has shown to be useful for identifying the period and the spatial structure of the dominant basin-scale oscillations. More detailed models are required to investigate these modes and their effects more thoroughly.

We found that the contribution of the internal waves to the mixing at the interior of the water column was weak, and we suggest that the most important mixing and dissipation region appears to be the turbulent bottom boundary layer driven by seiche currents.

\section{Acknowledgments}

We thank Ana C. Arbeláez, Daniel Largo, Hugo Escorcia, Juan Franco, and Mauricio Toro for their logistic support in the field and to Empresas Públicas de Medellin (EPM) for funding the field work and providing the hydrological data. We gratefully acknowledge the valuable suggestions provided by Hugo Ulloa and two anonymous reviewers during the preparation of this manuscript.

\section{Author contributions}

The present work shows some results of the Master's thesis of Andrés Posada-Bedoya under the supervision of Andrés Gómez-Giraldo and Ricardo Román-Botero. All the authors participated in the analysis and interpretation of the results, as well as in the drafting of the manuscript, the drawing of all the figures, and the preparation of the tables.

\section{Conflict of interests}

The authors declare that there is no conflict of interest of any kind that affects the publication of the results of our research work.

\section{References}

Anohin, V. V., Imberger, J., Romero, J. R., Ivey, G. N. (2006). Effect of Long Internal Waves on the Quality of Water Withdrawn from a Stratified Reservoir. Journal of Hydraulic Engineering. 132: 1134-1145.

Antenucci, J. P. \& Imberger, J. (2001). Energetics of long internal gravity waves in large lakes. Limnology and oceanography. 46 (7): 1760-1773.

Antenucci, J. P., Imberger, J., Saggio, A. (2000). Seasonal evolution of the basin-scale internal wave field in a large stratified lake. Limnology and Oceanography, 45: 1621-1638.

Bäuerle, E. (1998). Excitation on internal seiches by periodic forcing. In J. Imberger [ed.], Physical processes in lakes and oceans. Coastal and Estuarine Studies. V. 54. AGU. p. $167-178$.

Bendat, J. S. \& Piersol, A. G. (1986). Random data: analysis and measurement procedures. 2nd ed. Wiley. p. 605. 
Boegman, L., Imberger, J., Ivey, G. N., Antenucci, J. P. (2003). High-frequency internal waves in large stratified lakes. Limnology and Oceanography. 48: 895-919.

Bouffard, D., Boegman, L., Rao, Y. R. (2012). Poincaré waveinduced mixing in a large lake. Limnology and oceanography. 57 (4): 1201-1216.

Cortés, A., Fleenor, W., Wells, M., de Vicente, I., Rueda, F. (2014). Pathways of river water to the surface layers of stratified reservoirs. Limnology and Oceanography. 59 (1): $233-250$

Csanady, G. T. (1967). Large-scale motion in the Great Lakes. Journal of Geophysical Research. 72 (16): 4151-4162.

Csanady, G. T. (1972). Response of large stratified lakes to wind. Journal of Physical Oceanography. 2 (1): 3-13.

Cushman-Roisin, B., Tverberg V., Pavia, E.G. (1989). Resonance of internal waves in fjords: a finite-difference model. J. Mar. Res. 47: 547-567.

Eckert, W., Imberger, J., Saggio, A. (2002). Biogeochemical response to physical forcing in the water column of a warm monomictic lake. Biogeochemistry. 61 (3): 291-307.

Evans, M. A., MacIntyre, S., Kling, G. W. (2008). Internal wave effects on photosynthesis: Experiments, theory, and modeling. Limnology and Oceanography. 53 (1):339-353.

Fricker, P. D., Nepf, H. M. (2000). Bathymetry, stratification, and internal seiche structure. Journal of Geophysical Research. 105 (C6): 14237-14251.

Gill, A. E. (1982). Atmosphere-ocean dynamics. Academic. Press. London. p. 662.

Gilman, D. L., Fuglister, F. J., Mitchell Jr. J. M. (1963): On the power spectrum of "red noise". J. Atmos. Sci. 20: 182-184.

Gloor, M., Wüest, A., Imboden, D. M. (2000). Dynamics of mixed bottom boundary layers and its implications for diapycnal transport in a stratified, natural water basin. Journal of Geophysical Research: Oceans. 105 (C4): 8629-8646.

Gloor, M., Wüest, A., Münnich, M. (1994). Benthic boundary mixing and resuspension induced by internal seiches. Hydrobiologia. 284 (1): 59-68.

Gómez-Giraldo, A., Imberger, J., Antenucci, J. P. (2006). Spatial structure of the dominant basin-scale internal waves in Lake Kinneret. Limnology and Oceanography. 51 (1): 229-246.

Gómez-Giraldo, A., Imberger, J., Antenucci, J. P., Yeates, P. S. (2008). Wind-shear generated high-frequency internal waves as precursors to mixing in a stratified lake. Limnology and Oceanography. 53 (1): 354-367.

Gómez-Giraldo, E. A., Largo, D.C., Franco, J.D., RománBotero, R., Escorcia, H., Arbeláez, A.C. (2012). Caracterización de los procesos de transporte dominantes en los embalses Porce II, Riogrande II y La Fe. In: Palacio, J. (ed.), Informes técnicos embalses Porce II, Riogrande II y La Fe; "Estudio de la problemática ambiental de tres embalses de Empresas Públicas de Medellín para la gestión integral y adecuada del recurso hídrico". Universidad de Antioquia, Universidad Nacional de Colombia - Sede Medellín, Empresas Públicas de Medellín.

Heaps, N. S., Ramsbottom, A. E. (1966). Wind effects on water in a narrow two-layered lake. Phil. Trans. R. Soc. London, Ser. A. 259: 391-430.

Henderson, S. M. (2016). Turbulent production in an internal wave bottom boundary layer maintained by a vertically propagating seiche. Journal of Geophysical Research: Oceans. 121 (4): 2481-2498.
Henderson, S. M. \& Deemer, B. R. (2012). Vertical propagation of lakewide internal waves, Geophys. Res. Lett. 39. L06405.

Hingsamer, P., Peeters F., Hofmann H. (2014) The Consequences of Internal Waves for Phytoplankton Focusing on the Distribution and Production of Planktothrix rubescens. PLoS ONE. 9 (8): e104359.

Hogg, C. A., Egan, G. C., Ouellette, N. T., Koseff, J. R. (2018). Shoaling internal waves may reduce gravity current transport. Environmental Fluid Mechanics. 18 (2): 383-394.

Hondzo, M., Haider, Z. (2004). Boundary mixing in a small stratified lake. Water resources research. 40 (3): 1-12.

Horn, D. A., Imberger, J., Ivey, G. N. (2001). The degeneration of large-scale interfacial gravity waves in lakes. J. Fluid Mech. 434: 181-207.

Horn, W., Mortimer, C. H., Schwab, D. J. (1986). Wind-induced internal seiches in Lake Zurich observed and modeled. Limnology and Oceanography. 31 (6): 1232-1254.

Ibarra, G., De la Fuente, A., Contreras, M. (2015). Effects of hydropeaking on the hydrodynamics of a stratified reservoir: The Rapel Reservoir case study. Journal of Hydraulic Research. 53 (6): 760-772.

Imam, Y. E., Laval, B., Pieters, R., Lawrence, G. (2013). The strongly damped baroclinic response to wind in a multibasin reservoir. Limnology and Oceanography. 58 (4): 1243- 258.

Imberger, J. (1998). Flux paths in a stratified lake: A review. In J. Imberger (Editor), Physical processes in lakes and oceans. Coastal and Estuarine Studies. V. 54. AGU. pp. 1-17.

Imberger, J. \& Fandry, C. (1975). Withdrawal of a stratified fluid from a vertical two-dimensional duct. Journal of Fluid Mechanics. 70 (2): 321-332.

Largo-Gaviria, D. C. (2011). Spatio-temporal characterization of the thermal structure of Porce II reservoir. Master degree thesis, Univ. Nacional de Colombia, Medellín, Colombia.

Lemckert, C., Antenucci, J., Saggio, A., Imberger, J. (2004). Physical properties of turbulent benthic boundary layers generated by internal waves. Journal of Hydraulic Engineering. 130 (1): 58-69.

Lemmin, U. (1987). The structure and dynamics of internal waves in Baldeggersee. Limnology and Oceanography. 32: 43-61.

Lemmin, U., Mortimer, C. H., Bäuerle, E. (2005). Internal seiche dynamics in Lake Geneva. Limnology and Oceanography. 50: $207-216$.

Lewis Jr., W. M. (1987). Tropical limnology. Annual review of ecology and systematics. 18: 159-184.

Lewis Jr., W. M. (1996). Tropical lakes: How latitude makes a difference. Perspectives in tropical limnology. pp. 43-64. SPB Academic Publishing bv, Amsterdam, The Netherlands.

Lewis, W. M. (2000). Basis for the protection and management of tropical lakes. Lakes \& Reservoirs: Research \& Management. 5: 35-48.

Lorke, A., Peeters, F., Wüest, A. (2005). Shear-induced convective mixing in bottom boundary layers on slopes. Limnology and Oceanography. 50 (5): 1612-1619.

Lorrai, C., Umlauf, L., Becherer, J. K., Lorke, A., Wüest, A. (2011). Boundary mixing in lakes: 2. Combined effects of shear-and convectively induced turbulence on basin-scale mixing. Journal of Geophysical Research: Oceans. 116 (C10).

Maas, L. R. \& Lam, F.-P. A. (1995). Geometric focusing of internal waves. Journal of Fluid Mechanics. 300: 1-41.

MacIntyre, S. (1993). Vertical mixing in a shallow, eutrophic lake: Possible consequences for the light climate of phytoplankton. Limnology and Oceanography. 38 (4): 798-817. 
MacIntyre, S., Flynn, K. M., Jellison, R., Romero, J. R. (1999). Boundary mixing and nutrient fluxes in Mono Lake, California. Limnology and Oceanography. 44 (3): 512-529.

MacIntyre, S. \& Jellison, R. (2001). Nutrient fluxes from upwelling and enhanced turbulence at the top of the pycnocline in Mono Lake, California. In Saline Lakes, p. 13-29. Springer, Dordrecht.

Maurer, B. D. \& Linden, P. (2014). Intrusion-generated waves in a linearly stratified fluid. J. Fluid Mech. 752: 282-295.

Maxworthy, T., Lielich J., Simpson, J. E., Meiburg, E. H. (2002). Propagation of a gravity current in a linearly stratified fluid. J. Fluid Mech. 453: 371-394.

Miles, J. W. (1961). On the stability of heterogeneous shear flows. J. Fluid Mech. 10 (4): 496-508.

Monismith, S. G. (1985). Wind-forced motions in stratified lakes and their effect on mixedlayer shear. Limnology and Oceanography. 30: 771-783.

Monismith, S. (1987). Modal response of reservoirs to wind stress. Journal of Hydraulic Engineering. 113 (10): 1290-1304.

Mortimer, C. H. (1952). Water movements in lakes during summer stratification; evidence from the distribution of temperature in Windermere. Phil. Trans. R. Sot. Lond. Ser. B. 236: 355-404.

Mortimer, C. H. (1953). The resonant response of stratified lakes to wind. Schweizerische Zeitschrift für Hydrologie. 15 (1): 94-151.

Mortimer, C. H. (1974). Lake hydrodynamics. Verh. Int. Ver. Limnol. 20: 124-197.

Mortimer, C. H. (2004). Lake Michigan in motion: Responses of an inland sea to weather, earth-spin, and human activities. Univ of Wisconsin Press.

Münnich, M. (1996). The influence of bottom topography on internal seiches in stratified media. Dynamics of Atmospheres and Oceans. 23 (1-4): 257-266.

Münnich, M., Wüest, A., Imboden, D. M. (1992). Observations of the second vertical mode of the internal seiche in an alpine lake. Limnology and Oceanography. 37 (8): 1705-1719.

Nash, J. D. \& Moum, J. N. (2005). River plumes as a source of large-amplitude internal waves in the coastal ocean. Nature. 437 (7057): 400-403.

Nilssen, J. P. (1984). Tropical lakes - functional ecology and future development: The need for a process-orientated approach. Hydrobiologia. 113: 231-242.

Pannard, A., Beisner, B. E., Bird, D. F., Braun, J., Planas, D., Bormans, M. (2011). Recurrent internal waves in a small lake: potential ecological consequences for metalimnetic phytoplankton populations. Limnology and Oceanography: Fluids and Environments. 1 (1): 91-109.

Parinet, B., Lhote, A., Legube, B. (2004). Principal component analysis: an appropriate tool for water quality evaluation and management - application to a tropical lake system. Ecological Modelling. 178: 295-311.

Pérez-Losada, J., Roget, E., Casamitjana, X. (2003). Evidence of high vertical wave-number behavior in a continuously stratified reservoir: Boadella, Spain. Journal of Hydraulic Engineering. 129 (9): 734-737.

Pierson, D. C. \& Weyhenmeyer, G. A. (1994). High resolution measurements of sediment resuspension above an accumulation bottom in a stratified lake. Hydrobiologia. 284: 43-57.
Posada-Bedoya, A., Gómez-Giraldo, E. A., Román-Botero, R. (2017). Effect of density currents on the seasonal evolution of basin-scale internal waves in a Tropical Andean reservoir. 20th International Physical Processes in Natural Waters (PPNW) Workshop.

Preusse, M., Peeters, F., Lorke, A. (2010). Internal waves and the generation of turbulence in the thermocline of a large lake. Limnology and Oceanography. 55 (6): 2353-2365.

Román-Botero, R., Boegman, L., Gómez-Giraldo, A. (2017). Vertical mixing in a tropical Andean Reservoir, Porce II. 20th International Physical Processes in Natural Waters (PPNW) Workshop.

Rozas, C., de la Fuente, A., Ulloa, H., Davies, P., Niño, Y. (2014). Quantifying the effect of wind on internal wave resonance in Lake Villarrica, Chile. Environmental Fluid Mechanics. 14 (4): 849-871.

Schwab, D. J. (1977). Internal free oscillations in Lake Ontario. Limnology and Oceanography. 22 (4): 700-708.

Serra, T., Vidal, J., Casamitjana, X., Soler, M., Colomer, J. (2007). The role of surface vertical mixing in phytoplankton distribution in a stratified reservoir. Limnology and Oceanography. 52 (2): 620-634.

Shimizu, K. \& Imberger, J. (2008). Energetics and damping of basin-scale internal waves in a strongly stratified lake. Limnology and Oceanography. 53 (4): 1574-1588.

Shimizu, K., Imberger, J., Kumagai, M. (2007). Horizontal structure and excitation of primary motions in a strongly stratified lake. Limnology and Oceanography. 52 (6): 2641-2655.

Simpson, J. H., Wiles, P. J., Lincoln, B. J. (2011). Internal seiche modes and bottom boundary-layer dissipation in a temperate lake from acoustic measurements. Limnology and Oceanography. 56 (5):1893-1906.

Soares, M. C. S., Marinho, M. M., Huszar, V. L., Branco, C. W., Azevedo, S. M. (2008). The effects of water retention time and watershed features on the limnology of two tropical reservoirs in Brazil. Lakes \& Reservoirs: Research \& Management. 13 (4): 257-269.

Spigel, R. H. \& Imberger, J. (1980). The classification of mixedlayer dynamics of lakes of small to medium size. Journal of Physical Oceanography. 10 (7): 1104-1121.

Stevens, C. (1999). Internal waves in a small reservoir. J. Geophys. Res. Oceans. 104: 15777-15788.

Stevens, C., Lawrence, G., Hamblin, P., Carmack, E. (1996). Wind forcing of internal waves in a long narrow stratified lake. Dyn. Atmos. Oceans. 24: 41-50.

Stocker, R., Imberger, J. (2003). Energy partitioning and horizontal dispersion in a stratified rotating lake. J. Phys. Oceanogr. 33: 512-529.

Torrence, C., Compo, G. P. (1998). A practical guide to wavelet analysis. Bulletin of the American Meteorological Society. 79 (1): 61-78.

Ulloa, H. N., Constantinescu, G., Chang, K., Horna-Munoz, D., Steiner, O. S., Bouffard, D., Wüest, A. (2018). Hydrodynamics of a periodically wind-forced small and narrow stratified basin: A large-eddy simulation experiment. Environmental Fluid Mechanics. 19 (3): 667-698

Ulloa, H. N., Winters, K. B., de la Fuente, A., Niño, Y. (2015). Degeneration of internal Kelvin waves in a continuous twolayer stratification. Journal of Fluid Mechanics. 777: 68-96. 
Valerio, G., Pilotti, M., Luisa Marti, C., Imberger, J. (2012). The structure of basin-scale internal waves in a stratified lake in response to lake bathymetry and wind spatial and temporal distribution: Lake Iseo, Italy. Limnology and Oceanography. 57 (3): 772-786.

Vélez-Castaño, J. D., Gómez-Giraldo, A. (2013). Modelos multicapas para estimar el periodo de los modos naturales de oscilación en lagos y embalses tropicales. Tecnología y ciencias del agua. 4 (2): 171-183.

Vidal, J. \& Casamitjana, X. (2008). Forced Resonant Oscillations as a Response to Periodic Winds in a Stratified Reservoir. Journal of Hydraulic Engineering. 134 (4): 416-425.

Vidal, J., Casamitjana, X., Colomer, J., Serra, T. (2005). The internal wave field in Sau reservoir: Observation and modeling of a third vertical mode. Limnology and Oceanography. 50 (4): 1326-1333.
Vidal, J., Rueda, F. J., Casamitjana, X. (2007). The seasonal evolution of high vertical mode internal waves in a deep reservoir. Limnology and Oceanography. 52 (6): 2656-2667.

Wiegand, R. C. \& Chamberlain, V. (1987). Internal waves of the second vertical mode in a stratified lake. Limnology and Oceanography. 32 (1): 29-42.

Wüest, A. \& Lorke, A. (2003). Small-Scale Hydrodynamics in Lakes. Annual Review of Fluid Mechanics. 35 (1): 373-412.

Yeates, P. S., Gómez-Giraldo, A., Imberger, J. (2013). Observed relationships between microstructure patches and the gradient Richardson number in a thermally stratified lake. Environ. Fluid Mech. 13 (65): 205-226. 